\title{
Gonçalves Dias, a escravidão e o tapete levantado ${ }^{1}$
}

\section{Wilton José Marques}

\begin{abstract}
Resumo: O artigo faz uma leitura de Meditação, de Antônio Gonçalves Dias, publicada na revista Guanabara ao longo do primeiro semestre de 1850 . Nessa obra inacabada e ao contrário de seus pares românticos, o poeta critica a escravidão no Brasil. Palavras-chave: romantismo, Antônio Gonçalves Dias, Meditação, escravidão.
\end{abstract}

Abstract: The article makes a reading of Meditation, by Antônio Gonçalves Dias, published in Guanabara magazine over the first half of 1850. In this work unfinished and unlike their romantic couples, the poet criticizes that slavery in Brazil. Keywords: Romanticism, Antônio Gonçalves Dias, Meditação, slavery. romantismo brasileiro), financiada pela FAPESP. 


\section{A missão do vate}

No Brasil romântico, a principal missão de seus primeiros autores, e mais especificamente dos que cresceram à sombra programática de Gonçalves de Magalhães, foi a de configurar os elementos temáticos necessários tanto à definição da imagem quanto do discurso formador da nacionalidade brasileira. Nos anos subsequentes ao da independência política, e ainda escorada na retomada de um desejado nexo histórico, cuja função primordial era a de legitimar o novo status do país, a literatura romântica exerceu um papel fundamental no duplo processo de construção e disseminação da ideia de nação entre os brasileiros. Nesse mesmo sentido, o aparecimento literário de Gonçalves Dias, notadamente pela imediata ressonância pública de seus "poemas americanos", foi igualmente fundamental para o efetivo delineamento de um "nacionalismo propriamente literário". Entretanto, é importante ressaltar que a produção literária gonçalvina não se restringiu apenas à vertente indianista, também dialogou com outros temas inerentes à estética romântica, como o amor, a relação com a natureza, a religiosidade etc. Além do mais, o maranhense conseguiu encontrar algumas brechas que lhe permitiram expressar em outros textos, para talvez até melhor compreender o país, as várias e inerentes contradições que, desde sempre, permearam o cerne das relações de poder na sociedade oitocentista brasileira, incluindo-se aí o espinhoso problema da escravidão.

Primeiro autor local que, sem nenhuma hesitação, pode ser reconhecido como essencialmente romântico, e, assim, dotado de uma sensibilidade que o caracteriza como "gênio", isto é, aquele que, como verdadeiro vate e profeta, acredita ser o portador "de verdades ou sentimentos superiores aos dos outros homens" e, por isso mesmo, acredita ser "a nítida representação de um destino superior, regido por uma vocação superior”, ${ }^{2}$ Gonçalves Dias não somente assumiu para si a crença de que sua obra era revestida de um caráter de missão estético-social, como também se sentiu igualmente responsável para com os destinos do país. Para o poeta, contribuir literariamente para a consolidação do projeto civilizatório brasileiro, alçado de imediato à condição de principal bandeira de luta do movimento romântico local, passava pelo entendimento e pela consequente expressão das várias contradições sociais, o que, de alguma forma, já representava um primeiro passo para transformá-las.

Em outras palavras, havia por parte do poeta um forte desejo de fazer com que sua obra literária, ecoando até mesmo certos padrões morais de conduta, se tornasse um 
exemplo importante de intervenção social. Tal desejo se aplica, sobretudo, à Meditação (1850). Nesta obra, o poeta, como bem observou Antonio Candido, esboça uma larga visão poética do país, retratando:

[...] as suas raças, os escravos, os índios à margem do progresso, a iniquidade da vida política, as dificuldades de acertar - abrindo uma perspectiva otimista com o apelo ao patriotismo, chamado a cumular as lacunas da civilização e compensar, tanto as falhas dos governos quanto a indisciplina dos costumes públicos. ${ }^{3}$

Contrariando nesse sentido uma possível atitude passiva, num momento em que o silêncio de resignação ante as mazelas sociais do país talvez fosse a opção mais fácil entre os literatos românticos, que, em sua grande maioria, também eram funcionários públicos, Gonçalves Dias, então professor de latim e de história do Brasil no Imperial Colégio Pedro II, não apenas insistiu em tornar pública essa obra de juventude, que, apesar de inacabada, cristalizava sua visão crítica sobre o país, como também, para isso, escolheu um periódico emblemático para a consolidação do romantismo brasileiro: a revista Guanabara $(1849-56) .^{4}$

\section{Uma obra de juventude}

Apesar de ter sido publicada apenas ao longo do primeiro semestre de 1850, quando o poeta já era, por assim dizer, um autor consagrado e plenamente reconhecido nas letras nacionais, é importante não perder de vista que o fragmento de Meditação é, antes de tudo, uma obra de juventude. Em razão disso, é possível não apenas constatar que se, por um lado, nesse primeiro estágio a obra literária é muito mais infensa a possíveis influências estéticas, por outro, também apresenta algumas de suas principais matrizes temáticas, incluindo-se a própria questão do indianismo. Escrita concomitante à feitura dos últimos poemas que entrariam nos Primeiros cantos, essa obra singular de Gonçalves Dias foi produzida entre os anos de $1845 \mathrm{e}$

Pode-se dizer que a principal particularidade da revista Guanabara reside no fato de ela encerrar simbolicamente, pelo menos como manifestação de um propalado espírito de grupo, o percurso literário dos primeiros românticos que principiaram suas atividades em torno da revista Niterói (1836) e que posteriormente passaram pelas páginas da Minerva Brasiliense (1843-4). 
1846. ${ }^{5} \mathrm{Na}$ edição das Obras póstumas de Gonçalves Dias (1868-9), organizadas por Antonio Henriques Leal, é possível, inclusive, rastrear as datas de confecção dos três respectivos capítulos. Assim, segundo Leal, o capítulo I de Meditação foi concluído ainda em Caxias, no dia 23 de junho de 1845; o capítulo II, sem a especificação do dia, também foi concluído na cidade natal do poeta, em julho de 1845 , e, finalmente, o capítulo III foi terminado praticamente um ano depois em São Luís, no dia 8 de maio de $1846 .^{6}$

De saída, pode-se conjecturar que as datas indicam que Gonçalves Dias começou a escrever Meditação poucos meses depois de seu regresso de Coimbra, em março de 1845. Em janeiro do ano seguinte, o poeta viajou para São Luís, hospedando-se na casa de Teófilo Leal, já que, como escreveu ao amigo, em Caxias estava "sozinho em terra que, apesar de minha, eu posso chamar estranha". Na capital do Maranhão, concluiu o terceiro capítulo praticamente um mês antes de seguir, a bordo do vapor Imperador, para o Rio de Janeiro, em 14 de junho de 1846. Como se depreende de outra carta, esta datada de 3 de dezembro de 1846 , em que informa ter enviado ao amigo Teófilo o segundo capítulo de Meditação, Gonçalves Dias ainda explicita a sua intenção de fazer pelo menos mais um capítulo: "Irei continuando com ela [Meditação], e quero ver, se escrevo um capítulo em que trate dessa ideia da separação das Províncias do Norte do todo do Brasil".

De todo modo, e ainda que não tenha conseguido concluir aquele mencionado capítulo, essa obra inacabada de Gonçalves Dias, de nítida inspiração bíblica e escrita em versículos marcados por um forte estilo profético e messiânico, deve ter sido mesmo ideada ainda em Portugal, onde o poeta vivera de 1838 a 1845. Tendo, sobretudo no período em que estudara na Universidade de Coimbra entre 1840 e 1845, acompanhado de perto as constantes agitações políticas decorrentes das cisões e dos embates entre os liberais portugueses após o triunfo da guerra civil contra d. Miguel, o poeta, para construir em Meditação a sua visão de Brasil, inspirou-se muito provavelmente tanto em A voz do profeta (1836-7), escrito a propósito dos desdobramentos da Revolução de Setembro de 1836 pelo escritor português Alexandre Herculano (1810-77),

5 Para as datas dos últimos poemas, ver LEAL, Antonio Henriques. Antonio Gonçalves Dias - Notícia da sua vida e obras. Lisboa: Imprensa Nacional, 1875, p. 45-71.

6 DIAS, Antônio Gonçalves. Meditação. Obras póstumas de Gonçalves Dias. Antônio Henriques Leal (Org.). 2. ed., Rio de Janeiro; Paris: H. Garnier, v. 3, 1909, p. 19, 49 e 89.

7 Idem. Carta a Teófilo Leal, de $1^{\circ}$ de maio de 1845. Anais da Biblioteca Nacional - Correspondência ativa de Antônio Gonçalves Dias. Rio de Janeiro, v. 84, 1964, p. 38.

8 Idem. Carta a Teófilo Leal, de 3 de dezembro de 1846. Op. cit., p. 68-71. 
quanto no texto panfletário Palavras de um crente (1834), do padre francês Hugh Félicité Robert de Lamennais (1782-1848). ${ }^{9}$

\section{Generalidades: outro profeta?}

Em linhas gerais, os três capítulos, que compõem o texto de Meditação, articulam-se em torno de um diálogo travado entre um jovem e um velho sobre as possibilidades futuras de um país, que, pela leitura do texto, infere-se obviamente ser o Brasil. Dentro do texto, a personagem do jovem ainda ocupa a posição central de narrador. Por sua vez, o velho, além de representar em si a voz da experiência, é dotado de um caráter quase divino, pois, com a simples intervenção do toque de suas mãos sobre os olhos do rapaz, permite a este viajar pelo novo país. E tal viagem adquire um caráter peculiar, uma vez que ela não se realiza apenas do ponto de vista espacial, mas, sobretudo, do ponto de vista temporal. Em outras palavras, a ação do ancião faz com que o jovem possa ter acesso tanto ao presente quanto aos outros e diversos tempos históricos do Brasil. Por conta do ir e vir, o jovem, ao se defrontar com esses vários tempos e, por conseguinte, ao narrá-los, acaba assumindo uma postura semelhante à de um profeta que medeia (revelando) as relações entre os homens e os mistérios de Deus, inacessíveis a esses mesmos homens. Em sua essência, o profeta "designa o homem que fala ou o homem que é chamado, isto é, a quem foi dirigida uma palavra. Com efeito, a palavra é o meio de ação mais importante dos profetas; [...] é pela palavra que [eles] são verdadeiramente profetas" ${ }^{10}$ Como adentra numa "realidade inacessível" aos homens e, inclusive, superior ao seu próprio entendimento, o profeta, para traduzir o que vê, deve necessariamente lançar mão de uma linguagem simbólica e poética, cuja força metafórica resida justamente numa espécie de duplo poder, isto é, o de explicitar os significados de tais visões e o de, por tabela, levar os eventuais leitores a refletirem sobre a importância de tais significados.

Expressando-se através de uma espécie de palavra revelada, o jovem narrador de Meditação também se comporta como um profeta. Entretanto, no seu caso, ao contrário dos profetas bíblicos, a "realidade inacessível" a que teve acesso circunscreve-se apenas e tão somente ao Brasil. No limite, pode-se pensar que esse texto, esco-

Em 1836, o livro de Lammenais foi traduzido em Portugal, com tintas republicanas, por Antonio Feliciano de Castilho. Cf. LAMENNAIS, H. F. R. de. Palavras de um crente. Lisboa: Tipografia de A. I. S. de Bulhões, 1836.

Bíblia (tradução ecumênica). São Paulo: Edições Loyola, 1994, p. 319. 
rado na visão do gênio romântico, ambiciona mostrar as singularidades (positivas e negativas) do país aos próprios brasileiros, numa tentativa inocente ou não de ser a manifestação de uma autoconsciência coletiva. O tom que permeia o texto gonçalvino não tem um caráter eminentemente repressor e negativo, como, por exemplo, transparece na ira do narrador de $A$ voz do profeta, de Alexandre Herculano, mas sim, e isto talvez o aproxime de Palavras de um crente, de Lamennais, possui um caráter mais conciliador na medida em que não somente critica veementemente os problemas da sociedade brasileira, mas também não perde a oportunidade de indicar os possíveis caminhos para a superação de tais problemas.

Pensado dentro dessa perspectiva, e ao imitar a postura de guia e profeta, inerente ao gênio romântico, o comportamento do jovem narrador de Meditação reflete de certo modo tanto a postura quanto o desejo do próprio Gonçalves Dias de também interferir, ao menos literariamente, no processo de formação da sociedade brasileira.

\section{A primeira visão e a crítica}

De início, o problema que evidentemente salta aos olhos no primeiro capítulo de Meditação é, sem sombra de dúvida, o da escravidão. Em outras palavras, na primeira visão do jovem profeta, o problema apresenta-se através da constatação de que a sociedade brasileira assentava-se no trabalho escravo e, por conseguinte, dependia sobremaneira dele. Nesse sentido, tal condição, entranhada na estrutura socioeconômica do Brasil, tornava-se o maior empecilho, que obviamente deveria ser transposto, para que o país, enfim, pudesse alçar-se a um novo e desejado status de civilidade. Composto de seis partes, o capítulo começa a partir de uma primeira e mágica intervenção do velho sobre o jovem. Ao ter suas pálpebras tocadas pela "mão descarnada e macilenta" do ancião, o narrador, sem nunca perder a consciência, entra numa espécie de estado de transe. E, nessa condição, e sempre orientado pelo velho, parece ascender a outro plano. Será, portanto, dessa posição superior, desse ângulo de cima, que o jovem narrador terá acesso a uma visão geral, e privilegiada, do Brasil. Veja-se o início do texto:

Então o velho estendendo a mão descarnada e macilenta tocou as minhas pálpebras, que cintilaram como sentindo o contacto de um corpo eletrizado.

E diante dos meus olhos se estendeu uma corrente de luz suave e colorida, como a luz de uma aurora boreal. 
E o Ancião me disse: "Olha do norte ao sul - do ocaso ao nascer do sol - 'té onde alcançar a luz dos teus olhos, e dize-me o que vês".

E o seu gesto era soberano e tremendo, como o gesto de um monarca irritado.

E a sua voz solene e grave, como a voz do sacerdote que salmeia uma oração fúnebre em noite de enterramento.

E eu levei os meus olhos de norte a sul, do acaso ao nascer do sol, 'té onde eles alcançavam, e respondi: ${ }^{11}$

Mas, afinal, o que ele vê? Bem aos moldes das expectativas românticas locais, a impressão inicial do jovem profeta sobre o Brasil é marcada pela visão impactante de uma natureza exuberante e paradisíaca. Diante de seus olhos em êxtase, revela-se "uma prodigiosa extensão de terreno" que se mostra nas "árvores robustas e frondosas", na "relva densa e aveludada que o tapisa", nas "flores melindrosas e perfumadas", nas "aves canoras" e num "céu sereno e estrelado", que, por sua vez, cobre toda a extensão da "terra bendita". Entretanto, sobre a mesma "terra mimosa", o jovem também observa a existência de milhares de homens de fisionomias e cores discordes, que, colocados em posições definidas, formam o espectro da sociedade brasileira:

[...] vejo milhares de homens de fisionomias discordes, de cor vária e de caracteres diferentes.

E esses homens formam círculos concêntricos, como os que forma a pedra, caindo no meio das águas plácidas de um lago.

E os que formam os círculos externos têm maneiras submissas e respeitosas, são de cor preta; - e os outros, que são como um punhado de homens, formando o centro de todos os círculos, têm maneiras senhoris e arrogantes, e são de cor branca.

DIAS, Antônio Gonçalves, Meditação Guanabara, revista mensal, artística, científica e literária, Rio de Janeiro, tomo I, 1850, p. 102. (Os eventuais excertos da obra, aqui reproduzidos, serão atualizados ortograficamente, segundo as normas do padrão culto da língua portuguesa. Já quanto à pontuação, entendendo-a como característica inerente à expressividade romântica, esta será preservada tal como se apresenta nos textos, ainda que, em alguns momentos, isso possa significar menosprezo às regras atuais.) 
E os homens de cor preta têm as mãos presas em longas correntes de ferro, cujos anéis vão de uns a outros, eternos, como a maldição que passa de pais a filhos. ${ }^{12}$

Posta nesses termos, a visão de sociedade brasileira, expressa por Gonçalves Dias, não deixa entrever qualquer possibilidade de dúvida sobre o papel de mando exercido pelos brancos com suas "maneiras senhoris e arrogantes". Se se aprofundar aqui um pouco mais nessa metáfora do círculo, pensando-a somente em função da distância entre o centro do círculo e as suas extremidades, é possível ainda imaginar um suposto raio, que, partindo do centro, contenha, em óbvia gradação decrescente, todas as pessoas que, enfileiradas segundo suas respectivas importâncias sociais, representem os vários matizes da sociedade brasileira oitocentista. Insistindo ainda nessa imagem, uma famosa litografia do pintor francês Jean-Baptiste Debret pode muito bem servir de exemplo para corroborá-la. Na cena retratada, Debret apresenta um funcionário do governo que sai a passeio com a família. A despeito de ser apenas um funcionário do governo, a imagem ainda assim é válida, pois ela diz tudo, notadamente ao representar, em fila indiana, uma nítida e hierárquica disposição social. O próprio Debret descreve a cena:

A cena aqui desenhada representa a saída a passeio de uma família de fortuna média, cujo chefe é um funcionário do governo. Seguindo o antigo hábito ainda observado nessa classe, o chefe de família vai na frente, seguido imediatamente de seus filhos, enfileirados por ordem de idade, o mais moço sempre em primeiro; em seguida, vem a mãe, ainda grávida; atrás dela, sua criada de quarto, escrava mulata, infinitamente mais apreciada no serviço do que uma negra; em seguida a ama de leite, a escrava da ama de leite, o negro doméstico do senhor, um jovem escravo que está aprendendo o serviço; segue-se o novo negro, recém-comprado, escravo de todos os outros e cuja inteligência, mais ou menos viva, deve se desenvolver aos poucos à base de chicotadas. ${ }^{13}$

Dessa cena, para retomar a metáfora gonçalvina, interessa sobretudo a distância entre os extremos, isto é, o homem branco do centro e o último escravo, recém-comprado. A distância que os separa, colocando-os em posições radicalmente opostas na sociedade, explica por si que a submissão aos brancos, e a consequente manutenção dessa mesma sociedade, só poderia forçosamente ser regida e, ao mesmo tempo,

DIAS, Antônio Gonçalves, Meditação. Op. cit., p. 102-3. Ilustração e comentários de Jean-Baptiste Debret. São Paulo: Companhia das Letras, 2001, p. 36. 
sustentada "à base de chicotadas". No entanto, não se pode esquecer que, em vários momentos, essa idêntica lógica de violência também se traduziu num estado de permanente tensão entre brancos e negros. Assim, se, para o poeta, a natureza brasileira era prodigiosa e perfeita, a sociedade evidentemente não o era. A todo momento, e desde cedo, era sempre preciso demarcar e reafirmar, num contínuo exercício de poder, os papéis e lugares sociais que regiam tais relações de poder. É por isso que, já na terceira parte do primeiro capítulo de Meditação, o jovem profeta observa:

E eu falava ainda quando um mancebo, imberbe, saindo dentre os homens de cor branca, açoitou as faces de outro de cor preta com o reverso de sua mão esquerda.

E o ofendido, velho e curvado sob o peso dos anos, cruzou os braços, musculosos apesar da velhice, e deixou pender a cabeça sobre o peito.

E após um instante de silêncio profundo, arrojou-se aos pés de um ancião de cor branca, clamando justiça com voz abafada.

E um dentre estes, na flor da idade, ergueu-se iroso entre os dois anciãos de cabelos brancos e lançou por terra o injuriado, que pedia justiça. ${ }^{14}$

No Brasil oitocentista, dentro das tensas relações entre brancos e negros, não é novidade alguma que, como forma de dominação, a intimidação física sempre foi uma prática bastante comum. Tanto que, num livro famoso, muito lido pelas classes proprietárias do país, o Manual do agricultor brasileiro (1839), ${ }^{15}$ seu autor, Carlos Augusto Taunay, fiando-se na necessidade de disciplina como padrão básico de conduta na administração dos escravos, ensinava aos proprietários locais que o modo mais efetivo de manter, e por tabela perpetuar, a submissão dos escravos era, sobretudo, através da coação e da disseminação entre eles do medo. Pois, nas palavras do próprio Taunay, 
o preto, [...], é por natureza inimigo de toda ocupação regular, pois que muitas vezes prefere o jejum e a privação de todas as comodidades do trabalho que é justo que dê para o cumprimento do contrato, e só a coação e o medo poderão obrigar a dar conta de sua tarefa. ${ }^{16}$

Como atitude corriqueira, o recurso ao castigo físico, não raramente aplicado em excesso, transformava-se num verdadeiro exercício cotidiano de explicitação do poder senhorial, daí a necessária reafirmação de seu caráter real e, ao mesmo tempo, simbólico de dominação. Por outro lado, entre outras práticas, como atenuantes de uma possível reação à violência, incentivava-se ainda entre os negros a formação de casais e, mais importante, estimulava-se a doutrinação religiosa. Sem meias palavras, um texto redigido em 1854 por uma comissão de cafeicultores da região de Vassouras, no Rio de Janeiro, preocupada em traçar algumas instruções para controlar o risco de revoltas de escravos na região, conclamava os fazendeiros a promoverem

[...] por todos os meios o desenvolvimento de ideias religiosas entre os escravos, fazendo com que estes se confessem, ouçam missa o maior número de vezes e celebrem mesmo certas festas religiosas. $O$ fazendeiro que assim proceder, além de cumprir um dever cristão, tira grandes vantagens. A religião é um freio e ensina resignação. ${ }^{17}$

Aliás, nesse mesmo sentido, o próprio Gonçalves Dias compartilhava de opinião semelhante. Ao final de um famoso relatório sobre a situação da educação no Brasil, escrito em 1852, apenas dois anos após a publicação de Meditação, o poeta, discutindo as condições de índios e negros, reconhece ser perigoso dar instrução aos últimos. No entanto, ainda alerta as autoridades brasileiras sobre a necessidade de, ao menos, oferecer aos negros alguns rudimentos educacionais, notadamente religiosos, o que, em sua opinião, poderia, por um lado, evitar as "perturbações sociais" geradas através de reivindicações por "meios violentos", e, por outro, atenuar as influências das "devassidões de costume" sobre a mocidade:

Concluirei fazendo observar que duas grandes classes da nossa população não recebem ensino, nem educação alguma, - os índios e os escravos. No antigo regime era costume

TAUNAY, Carlos Augusto. Manual do agricultor brasileiro. Rafael de Bivar Marquese (Org.). São Paulo: Companhia das Letras, 2001, p. 64-5.

17 Apud Rafael de Bivar Marquese. Op. cit., p. 286. 
criarem-se cadeiras primárias nas localidades, em que se estabeleciam índios novamente convertidos. Se nos não convém ir procurar novos índios às florestas para os converter e civilizar, nem mesmo olharmos de perto para a instrução dos aldeados, é de necessidade atendermos ao menos essa outra classe, que entremeada com a população livre, tem sobre ela uma ação desmoralizadora, que não procuramos remediar. Quero crer perigoso dar-lhe instrução; mas por que não se dá uma educação moral e religiosa? Não será necessário prepará-los com muita antecedência para um novo estado a ver se evitamos perturbações sociais, que semelhantes atos têm produzido em outras partes, ou quando reivindicam por meios violentos - ou quando o governo imprudentemente generoso os surpreende com um dom intempestivo? Centenas de escravos existem por esses sertões, aos quais faltam as noções as mais símplices da religião e do dever, e que não sabem ou não compreendem os mandamentos de Deus. Educá-los, além de ser um dever religioso, é um dever social, por que a devassidão de costumes, que neles presenciamos, será um invencível obstáculo da educação da mocidade..$^{18}$

Entretanto, a despeito dessa opinião do poeta ou a despeito até do relativo sucesso dessas práticas atenuantes, a efetiva violência sobre os negros também implicava a possibilidade, igualmente real, de revide. No caso, seria uma reação direta das chamadas "vítimas-algozes", como mais tarde, em 1869, o romancista Joaquim Manuel de Macedo, em consonância direta com os debates políticos sobre a intervenção ou não do Estado nos estatutos da escravidão, intitularia justamente um livro seu, em que procura, através das três narrativas, conscientizar "os proprietários de escravos e convencê-los de que está em seus próprios interesses auxiliar o Estado na obra imensa e escabrosa da emancipação". ${ }^{19}$

De qualquer forma, para retomar a leitura de Meditação, Gonçalves Dias, na sequência da agressão do jovem imberbe ao velho negro, apresenta também em seu texto sinais evidentes de um forte desejo de reação solidária por parte dos escravos perante o agressor branco. Metaforicamente, se as vozes se calam, os elos das correntes tratam então de falar por si, anunciando ameaças e promessas de vinganças:

DIAS, Antonio Gonçalves. Relatório sobre a Instrução Pública em diversas províncias do Norte. Apud José Ricardo Pires de Almeida. História da Instrução Pública no Brasil (1500-1889). São Paulo: PUC-SP, 1989, p. 364-5.

19 MACEDO Joaquim Manuel de Macedo. Aos nossos leitores. Vítimas-algozes: quadros da escravidão. 3. ed., São Paulo: Scipione, 1991, p. 4. As narrativas que compõem o livro são as seguintes: "Simeão: o crioulo"; "Pai-Raiol: o feiticeiro" e "Lucinda: a mucama". 
E os elos da corrente, que manietava os homens de cor preta soltaram um som áspero e discorde, como o rugido de uma pantera.

E eu vi que esses homens tentavam desligar-se das suas cadeias, e que dos pulsos arrochados lhes corria o sangue sobre as algemas pesadas.

$\mathrm{E}$ vi que o ferro resistia às suas tentativas; mas também vi que a sua raiva era frenética, $\mathrm{e}$ que o sangue que lhes manava das feridas cerceava o ferro, como o enxofre incendido. ${ }^{20}$

Nessa última cena, explicitada simbolicamente pela "raiva frenética" que brotava de olhares e gestos, o possível recrudescimento das tensões é bruscamente interrompido pela imediata intervenção do velho sobre o jovem. No início da parte IV, aquele pediu a este que simplesmente afastasse seus olhos para longe "dos que sofrem e dos que fazem sofrer" e apenas os volvesse ao redor de si. Deixando para trás aquele "espetáculo lutuoso", a atenção do jovem volta-se então para as cidades, vilas e aldeias, disseminadas pela vasta extensão do império. Nelas, é possível ainda observar um fervilhar de homens, velhos e crianças, "correndo todos em direções diversas e com rapidez diferente, como homens carentes de juízos". Ao examinar com atenção as cidades, as vilas e as aldeias com suas "ruas tortuosas, estreitas e mal calçadas", suas "casas baixas, feias e sem elegância", seus "palácios sem pompa e sem grandeza", seus "templos sem dignidades e sem religião", o jovem profeta surpreende-se com a rústica e deplorável visão da realidade brasileira, que, sem maiores retoques, vai se configurando diante da perplexidade de seus olhos. Ele também se surpreende não somente com a constatação do grande número de escravos no país, mas, sobretudo, com a verdade de o braço escravo ter se transformado no principal sustentador dessa mesma realidade:

E nessas cidades, vilas e aldeias; nos seus cais, praças e chafarizes - vi somente - escravos!

E à porta ou no interior dessas casas mal construídas, e nesses palácios sem elegância escravos!

E no adro ou debaixo das naves dos templos, de costas para as imagens sagradas, sem temor como sem respeito - escravos! 
E nas jangadas mal tecidas, e nas canoas de um só toro de madeira - escravos; - e por toda parte - escravos!

Por isto o estrangeiro que chega a algum porto do vasto Império, consulta de novo a sua derrota, e observa atentamente os astros, porque julga que um vento inimigo o levou às costas d’África.

E conhece, por fim, que está no Brasil, a terra da liberdade, a terra ataviada de primores, e esclarecida por um céu estrelado e magnífico.

Mas grande parte da sua população é escrava; mas a sua riqueza consiste nos escravos; mas o sorriso, o deleite do seu comerciante, do seu agrícola e o alimento de todos os seus habitantes é comprado à custa do sangue e do suor do escravo.

E nos lábios do estrangeiro que aporta ao Brasil, desponta um sorriso irônico e despeitoso; e ele diz consigo que a terra da escravidão não poderá durar muito; porque é crente, e sabe que os homens são feitos do mesmo barro, sujeitos às mesmas dores e às mesmas necessidades. ${ }^{21}$

Essa passagem de Meditação é, sem dúvida, uma das mais contundentes em relação à escravidão. Nela, por um lado, é possível perceber que, revelada com a ajuda do olhar do estrangeiro, a perplexidade do jovem profeta apresenta-se na evidente contradição entre a imagem simbólica do Brasil, disseminada aos quatro ventos pelo romantismo, como um lugar ideal, como "a terra da liberdade" e sua celebrada natureza "ataviada de primores", e a imagem do Brasil real, cuja realidade e riqueza consistem somente nos escravos, cujo deleite de todos os seus habitantes "é comprado à custa do sangue e do suor do escravo". Até então, essa imagem nunca aparecera, de maneira tão explícita, em qualquer outra obra literária do país. No entanto, em Meditação, o dado curioso dessa revelação fica mesmo por conta da necessidade do aval do olhar estrangeiro. $\mathrm{O}$ mesmo olhar de fora, que já havia ensinado os poetas locais a enxergarem o país através do caráter exótico e simbólico da natureza brasileira, ${ }^{22}$

No "Ensaio sobre a história da literatura no Brasil", publicado na Revista Niterói (1836), Gonçalves de Magalhães, para se convencer e, ao mesmo tempo, convencer os escritores locais de que as "terras brasileiras" poderiam, com sua paisagem exótica, inspirá-los na sua missão de definir uma imagem 
ajudaria agora no entendimento da verdade de "que a terra da escravidão não pode durar muito". Esse ver pelos olhos do outro parece conferir à verdade um paradoxal status de mais verdade. Aliás, a própria percepção do poeta sobre a possibilidade de um estrangeiro, dado o número de escravos, achar que estava em terras africanas era bem comum. O comerciante inglês, John Luccock, por exemplo, faz semelhante observação ao afirmar em seu livro, quase ipsis litteris à ideia do poeta, que: "um estrangeiro que acontecesse de atravessar a cidade [do Rio de Janeiro] pelo meio dia, quase poderia supor-se transplantado para o coração da África”. ${ }^{23}$

Em suma, nesse trecho de Meditação, também é possível perceber uma evidente associação entre a precariedade das construções do país - ruas, cidades, palácios, templos - e o fato de elas terem sido realizadas pelo braço escravo. Sem muito esforço, essas construções imperfeitas podem, obviamente, ser associadas metaforicamente ao próprio processo de construção do Brasil. E aqui, tem-se a nítida impressão de que o poeta, através da visão do jovem, levanta, de propósito, o tapete imaginário que não permitia que os autores românticos mostrassem em suas obras o que, na verdade do dia a dia, todos viam, isto é, a realidade escravocrata do país.

Wilton José Marques é professor de Literatura Brasileira e Teoria Literária da Universidade Federal de São Carlos (UfSCar) e do Programa de Pós-Graduação em Estudos Literários da Universidade Estadual Paulista Júlio de Mesquita Filho (unesp/Araraquara), autor de Gonçalvez Dias: o poeta na contramão (EDUFSCar, 2010).

convincente de Brasil, ajustada às exigências dos novos tempos, apoiou-se incondicionalmente, enquanto testemunhos insuspeitos, nas diversas descrições da natureza tropical realizadas pelos viajantes e estudiosos europeus: "Nós vimos o céu, que cobre as ruínas do Capitólio, e as do Coliseu; sim, ele é belo; mas oh! que o do Brasil não Ihe cede em beleza! Falem por nós todos os viajores, que, por estrangeiros, de suspeitos não serão taxados. Sem dúvida fazem eles justiça, e o coração do Brasileiro, não tendo muito de ensoberbar-se quanto aos produtos das humanas fadigas, que só com o tempo se adquirem, enche-se, e palpita satisfeito, vendo as sublimes páginas de Langsdorff, Neuwied, Spix et Martius, Saint-Hilaire, Debret, e uma multidão de outros viajores, que as belezas de sua Pátria conhecidas fizeram à Europa. Cf. MAGALHÃES, Gonçalves de. Ensaio sobre a história da literatura do Brasil. Niteróy, Revista Brasiliense. Paris, Dauvin et Fontaine, Libraries, 1836 - São Paulo, edição fac-similada da Academia Paulista de Letras, v. 2, 1978, p. 132 e 135. (grifos meus) 